Rev. bras. zootec., v.28, n.3, p.605-613, 1999

\title{
Desempenho e Desenvolvimento Ponderal de Novilhas Leiteiras Alimentadas com Dietas à Base de Cana de Açúcar ${ }^{1}$
}

\author{
Lídia Ferreira Miranda 2 , Augusto César de Queiroz ${ }^{3}$, Sebastião Campos Valadares Filho ${ }^{3}$, \\ Paulo Roberto Cecon ${ }^{4}$, Elzânia Sales Pereira ${ }^{4}$, Mário Fonseca Paulino ${ }^{3}$, José Maurício de \\ Souza Campos ${ }^{3}$, José Rafael Miranda ${ }^{6}$
}

\begin{abstract}
RESUMO - O objetivo deste trabalho foi avaliar o desempenho e o desenvolvimento ponderal de novilhas alimentadas com dietas à base de cana-de-açúcar suplementadas com fontes de nitrogênio não-protéico (NNP) (uréia ou cama de frango, em substituição parcial da uréia) e, ou, adição de probióticos (sem probiótico, levedura ou microbiota ruminal). O custo e a margem bruta do uso destas dietas também foram analisados. Vinte e quatro novilhas, com idade e peso médio inicial de 15 meses e $247 \mathrm{~kg} \mathrm{PV}$, respectivamente, foram mantidas em baias individuais e alimentadas durante o período experimental de 84 dias. Os animais foram distribuídos em delineamento inteiramente casualisado, em esquema fatorial 2 x 3 (fonte de NNP vs fonte de probiótico), com quatro repetições. As novilhas foram pesadas e o perímetro torácico e a altura de cernelha e garupa foram determinados no início e no final do período experimental e a cada 28 dias. Os níveis de Nuréia plasmáticos das novilhas foram determinados em amostras de sangue coletadas imediatamente antes do fornecimento diário de alimento, zero hora, e às duas, quatro, seis e oito horas após a alimentação. Não houve interação entre fontes de nitrogênio e fontes de probióticos, para qualquer característica estudada. A suplementação da cana-de-açúcar com fontes NNP não apresentou diferença no ganho de peso diário dos animais. Entretanto, a adição de levedura ou microbiota ruminal promoveu ganhos semelhantes, porém superiores à sem adição de probióticos. A substituição parcial da uréia pela cama de frango não influenciou o desempenho das novilhas, mas as dietas suplementadas com levedura ou microbiota ruminal apresentaram maiores ganho de peso e desenvolvimento ponderal.
\end{abstract}

Palavras-chave: cama de frango, cana-de-açúcar, probiótico, uréia

\section{Performance and Ponderal Development of Dairy Heifers Fed Sugar Cane Based Diets}

\begin{abstract}
The objective of this work was to evaluate the performance, ponderal development of heifers fed sugar cane based diets, supplemented with non protein nitrogen (NPN) sources (urea or broiler litter, in replacement of urea) and, or, probiotics addition (without probiotic, with yeast or with ruminal microbiota). Cost and gross margin of the use of these diets were also evaluated. Twenty-four heifers, with age and average initial weight of 14 months and $247 \mathrm{~kg} \mathrm{LW}$, respectively, were maintained in individual stalls and ad libitum fed during the experimental of 84 days. The animals were distributed in a complete randomized design, in a 2 x 3 factorial arrangement (NPN source vs probiotic source), with four replicates. The heifers were weighed and their thoracic perimeter, hip and croup height were determined at the beginning and at the end of the experimental period and at every 28 days. The blood plasma N-urea levels of the heifers were also determined in blood samples collected immediately before the daily feed supply, zero hour, and at two, four, six and eight hours post feeding. There was no interaction between NPN sources and the probiotic sources, for any studied characteristic. The sugar cane supplementation with the NPN sources had no eefect on the average daily weight gain. However, the yeast or ruminal microbiota addition promoted similar weight gains, although, higher than without probiotic addition. The partial replacement of the urea for the broiler litter did not affect the heifers performance, but the diets supplemented with yeast or ruminal microbiota presented higher weight gain and ponderal development.
\end{abstract}

Key Words: broiler litter, sugar cane, probiotic, urea

\section{Introdução}

A cana-de-açúcar, como alimento básico para ruminantes, apresenta limitações de ordem nutricional, devido aos baixos teores de proteína, minerais e precursores gliconeogênicos e ao alto teor de fibra de baixa degradação ruminal (LENG, 1988); no entanto, segundo PAIVA et al. (1991), a deficiência de nitrogênio pode ser corrigida pelo fornecimento de fontes nitrogenadas não-protéicas. Dessa forma, a cana-deaçúcar suplementada com fontes de NNP passa a ser recurso forrageiro estratégico para proporcionar gan-

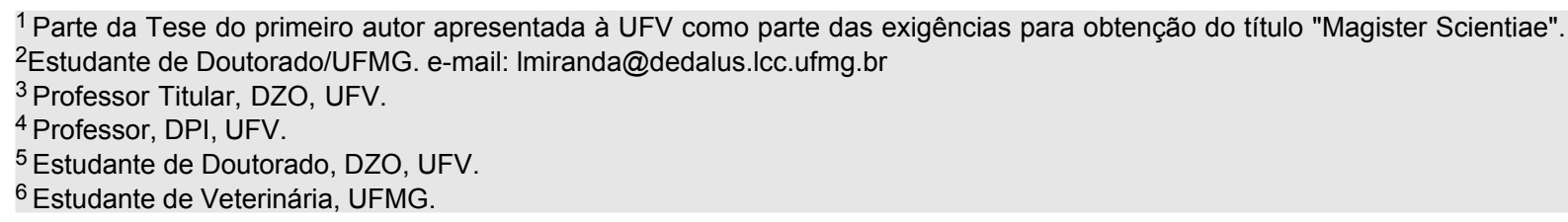


hos de peso moderados (MOREIRA et al., 1987) em ruminantes, constituindo-se em alternativa que permite economia de fontes convencionais de proteína além de minimizar custos. Entretanto, para aumentar a eficiência de utilização dessas dietas, tem-se utilizado suplementação com alimentos que forneçam proteínas sobrepassantes e precursores gliconeogênicos, como o farelo de algodão, em virtude de seus efeitos benéficos sobre a digestibilidade total dos alimentos e o consumo voluntário (AROEIRA et al., 1993).

A capacidade de um alimento ser ingerido pelo animal depende da ação de fatores que interagem em diferentes situações de alimentação, comportamento animal e meio ambiente. O consumo voluntário do animal, como tem sido proposto, é regulado por três mecanismos: o psicogênico, que envolve a resposta do animal a fatores inibidores ou estimuladores relacionados ao alimento ou ao ambiente; o fisiológico, em que a regulação é fornecida pelo balanço nutricional; e o físico, relacionado à capacidade de distensão do rúmen (MERTENS, 1992). Por conseguinte, tamanho e condição corporal, raça e status fisiológico são características relativas aos animais que influenciam o consumo, pois alteram as suas exigências, além da referida capacidade de distensão ruminal (VAN SOEST, 1994).

Segundo MERTENS (1985), o consumo de matéria seca em ruminantes é máximo para consumos de FDN de $1,2 \pm 0,1 \%$ do PV, para vacas leiteiras, atingindo valores de $1 \%$ para animais em fase de crescimento, quando 70 a $80 \%$ da FDN da ração foram fornecidos pela forragem. Dessa forma, o animal consome alimento até atingir a capacidade máxima de ingestão de FDN, que passa a inibir a ingestão (MERTENS, 1987), havendo limite de distensão ruminal, que determina a interrupção da ingestão voluntária (BAILE e FORBES, 1974).

O baixo consumo da cana-de-açúcar é atribuído à baixa degradação da sua fibra no rúmen, o que limita o consumo pelo enchimento, em conseqüência do acúmulo de fibra não-digerível neste compartimento (ORSKOV e HOVELL, 1978; RODRIGUEZ, 1995; e PEREIRA et al., 1996).

Os objetivos do presente trabalho foram avaliar o desempenho, o desenvolvimento ponderal de novilhas e a economicidade das dietas à base de cana-de-açúcar e farelo de algodão suplementadas com fontes de nitrogênio não-protéico (NNP) e, ou, adição de probióticos.

\section{Material e Métodos}

Vinte e quatro novilhas mestiças Holandês-Zebu, com idade média de 15 meses e peso médio inicial de $247 \mathrm{~kg}$, foram mantidas em baias individuais com piso cimentado, bebedouros, cochos de alimentação e área útil de $7 \mathrm{~m}^{2}$, sendo $1 / 3$ coberta com telhas de amianto. Os animais receberam 1,0 mL/50 kg PV de complexo vitamínico ADE, foram pesados, identificados por meio de brincos, vacinados contra febre aftosa e tratados contra endo e ectoparasitas.

O período de adaptação às dietas, às instalações e ao manejo experimental foi de 24 dias e o período experimental, de 84 dias. Para avaliar o desempenho e o desenvolvimento ponderal, os animais foram submetidos à pesagem individual, sendo determinados perímetro torácico, altura de cernelha e garupa de cada animal, no início e no fim do período experimental, e a cada 28 dias, sempre pela manhã, antes de receberem alimentação. Os pesos inicial e final foram a média das pesagens de dois dias consecutivos.

Foram utilizadas seis dietas experimentais à base de cana-de-açúcar (Saccharum officinarum, L.), suplementadas com duas fontes de nitrogênio nãoprotéico (NNP) - uréia ou cama de frango, em substituição parcial da uréia - e três fontes de probióticos, sem probiótico, com levedura ou com microbiota ruminal, mais farelo de algodão, fosfato bicálcico, calcário e sal no concentrado. A cama de frango usada foi à base de capim napier. As dietas foram elaboradas conforme as exigências estabelecidas pelo NRC (1989), para ganho médio de $0,54 \mathrm{~kg}$.

Os teores de matéria seca (MS), matéria orgânica (MO), fibra em detergente neutro (FDN), proteína bruta (PB), extrato etéreo (EE), cálcio, fósforo, potássio, sódio e magnésio da cana-de-açúcar, da cama de frango e dos concentrados utilizados na formulação das dietas, encontram-se na Tabela 1.

A relação volumoso:concentrado das dietas experimentais foi de 82:18 e 88:12 para as dietas suplementadas com uréia e cama de frango, em substituição parcial da uréia (tratamentos 1, 2, 3 e 4, 5, 6 , respectivamente). Todas as dietas foram formuladas para serem isoprotéicas, com aproximadamente $12 \%$ de proteína bruta na matéria seca. A composição percentual e química dos ingredientes utilizados nas dietas experimentais está apresentada na Tabela 2.

As dietas foram fornecidas, à vontade, uma vez ao dia, às $8 \mathrm{~h}$. A quantidade de dieta fornecida 
Rev. bras. zootec.

Tabela 1 - Composição químico-bromatológica (\%MS) da cana-de-açúcar, cama de frango e dos concentrados experimentais

Table 1 - Chemical composition (\%DM) of the sugar cane, broiler litter and experimental concentrates

\begin{tabular}{|c|c|c|c|c|}
\hline \multirow[t]{2}{*}{ Item } & \multirow[t]{2}{*}{$\begin{array}{l}\text { Cana-de-açúcar } \\
\text { Sugar cane }\end{array}$} & \multirow[t]{2}{*}{$\begin{array}{c}\text { Cama de frango } \\
\text { Broilerlitter }\end{array}$} & \multicolumn{2}{|c|}{$\begin{array}{c}\text { Concentrado } \\
\text { Concentrate }\end{array}$} \\
\hline & & & 1 & 2 \\
\hline Matéria seca & 25,50 & 81,29 & 84,67 & 86,49 \\
\hline Dry matter & & & & \\
\hline $\begin{array}{l}\text { Matéria orgânica } \\
\text { Organic matter }\end{array}$ & 21,72 & 57,85 & 74,37 & 72,52 \\
\hline $\begin{array}{l}\text { Fibra detergente neutro } \\
\text { Neutral detergent fiber }\end{array}$ & 60,35 & 62,95 & 53,18 & 48,78 \\
\hline Proteína bruta & 2,57 & 19,13 & 52,79 & 51,66 \\
\hline $\begin{array}{l}\text { Crude protein } \\
\text { Extrato etéreo } \\
\text { Etherextract }\end{array}$ & 0,49 & 0,30 & 0,41 & 0,58 \\
\hline $\mathrm{Ca}$ & 0,73 & 3,08 & 1,84 & 1,84 \\
\hline $\mathrm{F}$ & 0,20 & 1,30 & 0,90 & 1,15 \\
\hline $\mathrm{K}$ & 2,31 & 2,47 & 1,36 & 1,30 \\
\hline $\mathrm{Na}$ & 0,06 & 0,54 & 0,51 & 0,82 \\
\hline $\mathrm{Mg}$ & 0,21 & 0,49 & 0,37 & 0,43 \\
\hline
\end{tabular}

Tabela 2 - Composição percentual dos alimentos e químico-bromatológica das dietas (\%MS)

Table 2 - Percentage and chemical composition of the ingredients of the diets (\% DM)

\begin{tabular}{|c|c|c|c|c|c|c|}
\hline $\begin{array}{l}\text { Ingrediente } \\
\text { Ingredient }\end{array}$ & \multicolumn{6}{|c|}{$\begin{array}{c}\text { Tratamento } \\
\text { Treatment }\end{array}$} \\
\hline Cana-de-açúcar & 81,94 & 81,94 & 81,94 & 61,94 & 61,94 & 61,94 \\
\hline Sugar cane & & & & & & \\
\hline $\begin{array}{l}\text { Cama de frango } \\
\text { Broiler litter }\end{array}$ & - & - & - & 26,78 & 26,78 & 26,78 \\
\hline Farelo algodão & 14,99 & 14,99 & 14,99 & 9,55 & 9,55 & 9,55 \\
\hline $\begin{array}{l}\text { Cottonseed meal } \\
\text { Uréia }\end{array}$ & 1,81 & 1,81 & 1,81 & 1,03 & 1,03 & 1,03 \\
\hline $\begin{array}{l}\text { Urea } \\
\text { Fosfato bicálcio } \\
\text { Dicalcium phosphate }\end{array}$ & 0,42 & 0,42 & 0,42 & 0,40 & 0,40 & 0,40 \\
\hline $\begin{array}{l}\text { Calcário } \\
\text { Limestone }\end{array}$ & 0,61 & 0,61 & 0,61 & 0,59 & 0,59 & 0,59 \\
\hline $\begin{array}{l}\text { Sal } \\
\text { Salt }\end{array}$ & 0,23 & 0,23 & 0,23 & 0,24 & 0,24 & 0,24 \\
\hline $\begin{array}{l}\text { Matéria seca } \\
\text { Dry matter }\end{array}$ & 29,20 & 29,20 & 29,20 & 35,76 & 35,76 & 35,76 \\
\hline $\begin{array}{l}\text { Protéina bruta } \\
\text { Crude protein }\end{array}$ & 11,70 & 11,70 & 11,70 & 12,78 & 12,78 & 12,78 \\
\hline $\begin{array}{l}\text { Fibra detergente neutro } \\
\text { Neutral detergent fiber }\end{array}$ & 59,05 & 59,05 & 59,05 & 59,68 & 59,68 & 59,68 \\
\hline $\begin{array}{l}\text { Matéria orgânica } \\
\text { Organic matter }\end{array}$ & 31,22 & 31,22 & 31,22 & 37,38 & 37,38 & 37,38 \\
\hline $\mathrm{Ca}$ & 0,93 & 0,93 & 0,93 & 1,48 & 1,48 & 1,48 \\
\hline $\mathrm{F}$ & 0,32 & 0,32 & 0,32 & 0,59 & 0,59 & 0,59 \\
\hline K & 2,13 & 2,13 & 2,13 & 2,23 & 2,23 & 2,23 \\
\hline $\mathrm{Na}$ & 0,14 & 0,14 & 0,14 & 0,26 & 0,26 & 0,26 \\
\hline $\mathrm{Mg}$ & 0,23 & 0,23 & 0,23 & 0,31 & 0,31 & 0,31 \\
\hline
\end{tabular}

$110 \mathrm{~g}$ de levedura/animal/dia (10 $\mathrm{g}$ of yeast/animal/day).

$210 \mathrm{~g}$ de microbiota ruminal/animal/dia (10 g of ruminal microbiota/animal/day). 
diariamente foi reajustada de acordo com o consumo do dia anterior, para que houvesse sobra de $10 \%$ do total fornecido, a fim de garantir ingestão voluntária e grau de seleção uniforme de cada animal.

As amostras das dietas experimentais e das sobras dos cochos de cada novilha foram pesadas e amostradas diariamente. Apenas $5 \%$ do total das sobras produzidas/animal/dia foram acondicionados em sacolas plásticas e congeladas a $-18^{\circ} \mathrm{C}$. As amostras foram descongeladas à temperatura ambiente, no final de cada período experimental, misturadas e homogeneizadas manualmente, formando-se amostras compostas dos alimentos e das sobras, por animal e período. As amostras compostas, aproximadamente 100 gramas, foram acondicionadas em sacos de papel, fazendo-se a pré-secagem em estufa a $60^{\circ} \mathrm{C}$, com ventilação forçada de ar, onde permaneceram por 96 horas. Estes materiais foram então moídos em moinhos de faca do tipo "Willey", com peneira de 30 mesh e, posteriormente, armazenados em recipientes de vidro com tampa de polietileno, para posteriores análises laboratoriais.

Foram realizadas determinações de matéria seca (MS), em estufa a $105^{\circ} \mathrm{C}$, proteína bruta (PB) e extrato etéreo (EE), conforme a recomendação da AOAC (1975). A fibra em detergente neutro (FDN) foi determinada pelo método proposto por Van Soest e Wine (1968), citados por SILVA (1990). As determinações de matéria orgânica (MO) das amostras foram realizadas por meio do uso de mufla a $600^{\circ} \mathrm{C}$, segundo metodologia descrita por SILVA (1990). Os teores de cálcio e magnésio foram determinados pelo método de absorção atômica; os de fósforo, por método colorimétrico; e os de sódio e potássio, por fotometria de chama (SILVA, 1990).

Foram coletadas amostras de sangue através da veia jugular, imediatamente antes do fornecimento diário de alimento, zero hora, e às duas, quatro, seis e oito horas pós-prandial, para posterior determinação de uréia plasmática, segundo o método diacetil modificado (Kit analisa). Os resultados foram interpretados por meio de análises de variância e regressão.

O delineamento experimental utilizado foi o inteiramente casualisado em esquema fatorial 2 x 3 (duas fontes de nitrogênio não-protéico $\mathrm{x}$ três fontes de probiótico) com quatro repetições.

Os dados experimentais obtidos nos diversos tratamentos foram submetidos às análises de variância e as médias foram comparadas pelo teste de Tukey, a 1 e $5 \%$ de probabilidade, utilizando-se o pacote computacional SAEG (Sistema de Análise Estatística e
Genética), UFV (1995), segundo o modelo estatístico:

em que

$$
\mathrm{Y}_{\mathrm{ijr}}=\mu+\mathrm{N}_{\mathrm{i}}+\mathrm{P}_{\mathrm{j}}+\mathrm{NP}_{\mathrm{ij}}+\mathrm{e}_{\mathrm{ijr}}
$$

$\mathrm{Y}_{\mathrm{ijr}}=$ observação referente ao animal $\mathrm{r}$ na fonte de nitrogênio i e do probiótico j;

$\mu=$ média geral;

$\mathrm{N}_{\mathrm{i}}=$ efeito da fonte de nitrogênio $\mathrm{i}(\mathrm{i}=1,2)$;

$\mathrm{P}_{\mathrm{j}}=$ efeito do probiótico $\mathrm{j}(\mathrm{j}=1,2,3)$;

$\mathrm{NP}_{\mathrm{ij}}=$ efeito da interação fonte de nitrogênio $\mathrm{x}$ probiótico; e

$\mathrm{e}_{\mathrm{ijr}}=$ erro aleatório associado a cada observação $(\mathrm{r}=1,2,3,4)$;

Para avaliar a economicidade das dietas, considerou-se apenas o custo com alimentação e que todas as novilhas fossem iguais em valor e potencial para produção de leite.

No cálculo das despesas, considerou-se o preço dos ingredientes, segundo dados da Fábrica de Rações da Universidade Federal de Viçosa. Para cálculo das receitas, considerou-se o preço da arroba de novilha como o dobro do preço médio, nos últimos dez anos, da arroba do boi gordo, segundo ANUALPEC 97 (1997).

\section{Resultados e Discussão}

A interação entre as fontes de nitrogênio nãoprotéico e as fontes de probióticos não foi significativa para qualquer característica estudada.

Os valores médios diários do ganho de peso e consumo de MS, FDN e PB, em kg/dia, \% PV e $\mathrm{g} / \mathrm{kg}^{0,75}$, para novilhas mestiças recebendo dietas com fonte de nitrogênio não-protéico (uréia ou cama de frango, em substituição parcial da uréia) e fonte de probióticos (sem probiótico, com levedura, ou com microbiota ruminal), encontram-se na Tabela 3.

A suplementação da cana-de-açúcar com as fontes de nitrogênio não-protéico, uréia ou cama de frango não apresentou diferença no ganho de peso, independente da forma pela qual o ganho de peso foi expresso. Entretanto, a adição de levedura ou de microbiota ruminal promoveu ganhos semelhantes, porém superiores $(\mathrm{P}<0,01)$ às dietas sem suplementação. As dietas com probióticos apresentaram ganho de peso $26 \%$ acima da média calculada de $0,547 \mathrm{~kg} /$ dia.

A substituição parcial da uréia pela cama de frango influenciou $(\mathrm{P}<0,01)$ a ingestão de matéria seca (MS), fibra em detergente neutro (FDN) e proteína bruta (PB), em $\mathrm{kg} / \mathrm{dia}, \% \mathrm{PV}$ e $\mathrm{g} / \mathrm{kg}^{0,75}$, observando-se maior ingestão de nutrientes para as dietas suplementadas com cama de frango. Apesar 
Rev. bras. zootec.

Tabela 3 - Média do ganho de peso diário e consumo de MS, FDN e PB

Table 3 - Average daily gain and DM, NDF and CP intake

\begin{tabular}{|c|c|c|c|c|c|c|}
\hline \multirow[t]{2}{*}{ Item } & \multicolumn{2}{|c|}{$\begin{array}{l}\text { Fonte de NNP } \\
N P N \text { source }\end{array}$} & \multicolumn{3}{|c|}{$\begin{array}{l}\text { Fonte de probiótico } \\
\text { Probiotic source }\end{array}$} & \multirow[b]{2}{*}{$\mathrm{CV}(\%)$} \\
\hline & $\begin{array}{l}\text { Uréia } \\
\text { Urea }\end{array}$ & $\begin{array}{c}\text { Cama de frango } \\
\text { Broiler litter }\end{array}$ & $\begin{array}{c}\text { Sem } \\
\text { Withou }\end{array}$ & $\begin{array}{c}\text { Levedura } \\
\text { Yeast }\end{array}$ & $\begin{array}{l}\text { Microbiota ruminal } \\
\text { Ruminal microbiota }\end{array}$ & \\
\hline \multicolumn{7}{|c|}{ Peso vivo (Live weight) } \\
\hline $\begin{array}{l}\text { PV inicial kg } \\
\text { Initial } L W \mathrm{~kg}\end{array}$ & 261,29 & 266,41 & 268,43 & 262,75 & 260,37 & 13,05 \\
\hline $\begin{array}{l}\text { PV final kg } \\
\text { Final } L W \mathrm{~kg}\end{array}$ & 314,85 & 317,89 & 310,93 & 318,37 & 319,81 & 11,82 \\
\hline \multicolumn{7}{|c|}{ Ganho de peso (Daily weight gain) } \\
\hline $\mathrm{kg} / \mathrm{dia}$ & 0,64 & 0,62 & $0,51^{\mathrm{b}}$ & $0,67^{\mathrm{a}}$ & $0,71^{\mathrm{a} * *}$ & 14,43 \\
\hline$\% \mathrm{PV}$ & 0,20 & 0,19 & $0,16^{b}$ & $0,21^{\mathrm{ab}}$ & $0,22^{a} * *$ & 13,51 \\
\hline $\mathrm{g} / \mathrm{kg},{ }^{75}$ & 8,61 & 8,24 & $6,94^{\mathrm{b}}$ & $8,87^{\mathrm{a}}$ & 9,48 a $* *$ & 12,90 \\
\hline \multicolumn{7}{|c|}{ Consumo MS (DM intake) } \\
\hline $\mathrm{kg} / \mathrm{dia}$ & $6,25^{b}$ & 7,31 a $* *$ & 6,33 & 7,15 & 6,86 & 11,45 \\
\hline$\% \mathrm{PV}$ & $1,98^{b}$ & $2,30^{\mathrm{a} * *}$ & $2,04^{\mathrm{b}}$ & $2,25^{\mathrm{a}}$ & $2,14^{\mathrm{ab} * *}$ & 4,99 \\
\hline $\mathrm{g} / \mathrm{kg}^{0,75}$ & $83,61^{\mathrm{b}}$ & $97,15^{a} * *$ & $85,47^{\mathrm{b}}$ & $94,96^{\mathrm{a}}$ & $90,70 \mathrm{ab} * *$ & 5,22 \\
\hline \multicolumn{7}{|c|}{ Consumo FDN (NDF intake) } \\
\hline $\mathrm{kg} / \mathrm{dia}$ & $3,60^{b}$ & 4,28 a $* *$ & 3,68 & 4,17 & 3,97 & 12,74 \\
\hline$\% \mathrm{PV}$ & $1,14^{\mathrm{b}}$ & 1,35 a $* *$ & $1,18^{\mathrm{b}}$ & $1,31^{\mathrm{a}}$ & $1,24^{\mathrm{ab} *}$ & 6,07 \\
\hline $\mathrm{g} / \mathrm{kg}^{0,75}$ & $48,03^{b}$ & $56,90^{a * *}$ & $49,55^{\mathrm{b}}$ & $55,39^{a}$ & $52,45^{\mathrm{ab}} *$ & 6,75 \\
\hline \multicolumn{7}{|c|}{ Consumo PB (CP intake) } \\
\hline $\mathrm{kg} / \mathrm{dia}$ & $0,78^{b}$ & $0,97^{\mathrm{a} * *}$ & 0,82 & 0,92 & 0,89 & 10,39 \\
\hline$\% \mathrm{PV}$ & $0,25^{b}$ & $0,30^{a} * *$ & $0,26^{\mathrm{b}}$ & $0,29^{a}$ & $0,28 \mathrm{ab} *$ & 5,26 \\
\hline $\mathrm{g} / \mathrm{kg}^{0,75}$ & $10,51^{b}$ & $12,87^{\mathrm{a} * *}$ & $11,10^{\mathrm{b}}$ & $12,22^{\mathrm{a}}$ & $11,75^{\mathrm{ab} * *}$ & 5,09 \\
\hline
\end{tabular}

$a, b$
$1 \mathrm{~kg} / \mathrm{dia}, \% \mathrm{PV}$ e g/kg ${ }^{0,75}\left(\mathrm{~kg} /\right.$ day, $\%$ LW and $\left.\mathrm{g} / \mathrm{kw} \cdot{ }^{75}\right)$.

de as porcentagens de FDN das dietas serem bem próximas, as dietas suplementadas com cama de frango apresentaram mais 6,56 unidades percentuais de MS, em relação às dietas com uréia, o que, provavelmente, explica a maior ingestão de MS, FDN e PB dessas dietas, considerando-se que o consumo de matéria natural $(\mathrm{MN})$ foi o mesmo. Em relação à fonte de probiótico, não se observou diferença na ingestão de MS, FDN e PB, em kg/dia, entre as dietas; contudo, a ingestão de MS, FDN e PB, em $\% \mathrm{PV}$ e $\mathrm{g} / \mathrm{kg}^{0,75}$, foi diferente $(\mathrm{P}<0,05)$ entre os animais que receberam dieta suplementada com probióticos (levedura ou microbiota ruminal) em relação à sem probiótico (Tabela 3). Dessa forma, observou-se tendência de maior consumo para as dietas suplementadas com levedura, seguidas das dietas suplementadas com microbiota ruminal (Tabela 3 ). OLIVEIRA (1998) e SILVA (1998), entretanto, relataram que a utilização diária de $10 \mathrm{~g} / \mathrm{animal} / \mathrm{dia}$ de microbiota ruminal não influenciou o consumo de nutrientes, em $\mathrm{kg} / \mathrm{dia}, \% \mathrm{PV}$ e $\mathrm{g} / \mathrm{kg}^{0,75}$.

Os resultados da ingestão de FDN para as dietas suplementadas com uréia e cama de frango $(1,14$ e $1,35 \% \mathrm{PV}$, respectivamente) mostraram que os animais ingeriram acima de sua capacidade ótima de consumo de FDN, que segundo MERTENS (1985) é de 1\% do PV para animais em crescimento. Como o conteúdo de parede celular das dietas estava acima de $50 \%$ da MS da forragem, provavelmente, a ingestão voluntária foi regulada pela limitação física do trato gastrintestinal (VAN SOEST, 1965), havendo assim limite de distensão ruminal, que determina a interrupção da ingestão voluntária (BAILE eFORBES, 1974). Dessa forma, a ingestão de MS e energia ficou restrita, devido ao volume do rúmen ocupado pela massa de fibra.

Entretanto, observa-se que foi projetado ganho de peso moderado de $0,547 \mathrm{~kg} /$ dia para as dietas; portanto, pode-se inferir que a FDN não influenciou a ingestão para o nível de produção esperado, já que os ganhos de peso obtidos foram maiores que os projetados. MERTENS (1987) relata ser importante que o teor de FDN não limite a ingestão, para que os animais sejam capazes de consumir quantidades suficientes de matéria seca que atendam às suas necessidades energéticas, não influenciando a produção.

Como a maioria das dietas com cana-de-açúcar, no Brasil, assemelham-se às deste trabalho, observase que, em virtude do elevado teor de FDN dessas 


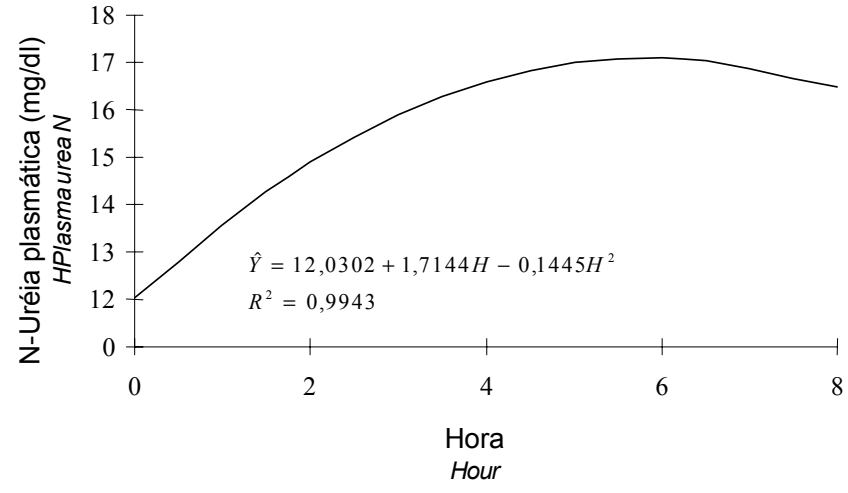

Figura 1 - Regressão da concentração plasmática de Nuréia, em relação às horas após alimentação.

Figure 1 - Regression of the plasma urea $N$ concentrations on the hours after feeding. dietas, condição usual de alimentação, os ruminantes raramente ingerem energia suficiente para atender as suas produções potenciais (VAN SOEST, 1991); dessa forma, os animais obtiveram taxa de ganho de peso moderado em relação à categoria de novilhas em terminação que poderiam apresentar ganhos em torno de $1,0 \mathrm{~kg} / \mathrm{dia}$, sendo que a distensão, provavelmente, foi o fator dominante que influiu no consumo das dietas de baixa qualidade.

As médias de desempenho ponderal e eficiência de utilização da MS e PB das novilhas encontram-se na Tabela 4.

Quanto ao desenvolvimento ponderal, não foi observada diferença em relação ao perímetro torácico, à altura de cernelha e à altura de garupa entre as

Tabela 4 - Desempenho ponderal e eficiência do uso de MS e PB Table 4 - Ponderal development and efficiency of use of DM and CP

\begin{tabular}{|c|c|c|c|c|c|c|}
\hline \multirow[t]{2}{*}{ Item } & \multicolumn{2}{|c|}{$\begin{array}{c}\text { Fonte de nitrogênio } \\
\text { Nitrogen source }\end{array}$} & \multicolumn{3}{|c|}{$\begin{array}{l}\text { Fonte de probiótico } \\
\text { Probiotic source }\end{array}$} & \multirow[b]{2}{*}{$\mathrm{CV}(\%)^{1}$} \\
\hline & $\begin{array}{l}\text { Uréia } \\
\text { Urea }\end{array}$ & $\begin{array}{c}\text { Cama de frango } \\
\text { Broiler litter }\end{array}$ & $\begin{array}{c}\text { Sem } \\
\text { Without }\end{array}$ & $\begin{array}{l}\text { Levedura } \\
\text { Yeast }\end{array}$ & $\begin{array}{c}\text { Microbiota ruminal } \\
\text { Ruminal microbiota }\end{array}$ & \\
\hline Número de animais & 12 & 12 & 8 & 8 & 8 & \\
\hline Number of animals & & & & & & \\
\hline $\begin{array}{l}\text { Perímetro torácico inicial, } \mathrm{cm} \\
\text { Initial thoracic perimeter }\end{array}$ & 149,91 & 149,70 & 149,06 & 151,68 & 148,68 & \\
\hline $\begin{array}{l}\text { Perímetro torácico final, } \mathrm{cm} \\
\text { Final thoracic perimeter }\end{array}$ & 156,87 & 156,41 & 155,56 & 159,56 & 154,56 & \\
\hline $\begin{array}{l}\text { Diferença }(\mathrm{I}-\mathrm{F}), \mathrm{cm} / \text { dia } \\
\text { Difference }(I-F), \mathrm{cm} / \text { day }\end{array}$ & 0,08 & 0,07 & 0,07 & 0,08 & 0,08 & 31,07 \\
\hline $\begin{array}{l}\text { Altura cernelha inicial, } \mathrm{cm} \\
\text { Inicial hip height }\end{array}$ & 120,37 & 114,58 & 113,31 & 114,75 & 114,06 & \\
\hline $\begin{array}{l}\text { Altura cernelha final, } \mathrm{cm} \\
\text { Final hip height }\end{array}$ & 120,71 & 119,08 & 120,68 & 120,12 & 118,87 & \\
\hline $\begin{array}{l}\text { Diferença }(\mathrm{I}-\mathrm{F}), \mathrm{cm} / \mathrm{dia} \\
\text { Difference }(I-F) \mathrm{cm} / \text { day }\end{array}$ & 0,05 & 0,05 & 0,04 & 0,06 & 0,05 & 40,35 \\
\hline $\begin{array}{l}\text { Altura garupa inicial, } \mathrm{cm} \\
\text { Initial croup height }\end{array}$ & 121,16 & 120,58 & 120,12 & 122,00 & 120,50 & \\
\hline $\begin{array}{l}\text { Altura garupa final, } \mathrm{cm} \\
\text { Final croup height }\end{array}$ & 124,96 & 124,71 & 123,56 & 126,43 & 124,50 & \\
\hline $\begin{array}{l}\text { Diferença }(\mathrm{I}-\mathrm{F}), \mathrm{cm} / \text { dia } \\
\text { Difference }(I-F), c m / \text { day }\end{array}$ & 0,05 & 0,04 & $0,03^{\mathrm{b}}$ & $0,06^{\mathrm{a}}$ & $0,05^{\mathrm{ab} * *}$ & 34,69 \\
\hline $\begin{array}{l}\text { Eficiência de utilização da MS } \\
\text { (Ganho/consumo MS) }\end{array}$ & $0,85^{\mathrm{a}}$ & $0,40^{\mathrm{b} * *}$ & 0,58 & 0,50 & 0,79 & 47,88 \\
\hline $\begin{array}{l}\text { Efficiency of utilization of DM } \\
\text { (Gain/DM intake) }\end{array}$ & & & & & & \\
\hline $\begin{array}{l}\text { Eficiência de utilização da PB } \\
\text { (Ganho/consumo PB) } \\
\text { Efficiency of utilization of CP } \\
\text { (Gain/CP intake) }\end{array}$ & $0,80^{\mathrm{a}}$ & $0,62^{b * *}$ & $0,61^{\mathrm{b}}$ & $0,73^{a b}$ & $0,81^{\mathrm{a} * *}$ & 13,54 \\
\hline
\end{tabular}


dietas suplementadas com uréia ou cama de frango, em substituição parcial da uréia. Com a adição dos probióticos à dieta, observou-se aumento $(\mathrm{P}<0,01)$ da altura de garupa em relação à sem adição. Entretanto, o perímetro torácico e a altura de cernelha não diferiram com a adição de probióticos.

Segundo RADCLIFF et al. (1997), apenas informações com relação ao peso corporal não são suficientes para a descrição do animal, pois um animal pode ser baixo e gordo e pesar mais que um animal alto e magro. Dessa forma, a altura da cernelha e altura de garupa são mensurações utilizadas para estimar o tamanho do esqueleto, que é de suma importância ao parto, no intuito de evitar distocia ou desordens metabólicas pós-parto, pois novilhas menores e gordas são mais propensas a apresentar maior incidência desses problemas.

O maior ganho de peso, a altura de garupa e o consumo de matéria seca para as dietas suplementadas com levedura ocorreram, provavelmente, porque a cultura de levedura promoveu aumento no número de bactérias celulolíticas, o que melhorou a degradação da fibra, apresentou maior fluxo de proteína microbiana do rúmen, proporcionou maior consumo de alimento e melhorou a eficiência alimentar (NEWBOLD et al., 1995; WALLACE,1994).

Os animais que receberam apenas uréia como fonte de NNP apresentaram melhor $(\mathrm{P}<0,01)$ eficiência de utilização de matéria seca e proteína bruta que a cama de frango associada à uréia. Os animais que receberam a adição de probióticos (levedura ou microbiota ruminal) na dieta apresentaram eficiência de utilização da proteína semelhante, porém superior $(\mathrm{P}<0,01)$ à sem suplementação.

As médias das concentrações plasmáticas de Nuréia em $\mathrm{mg} / \mathrm{dL}$ não diferiram entre as dietas experimentais, resultando na seguinte equação de regressão, em função das horas pós-prandial $(\mathrm{H})$ : $\mathrm{N}$-uréia plasmática $=$ $12,0302+1,7144 \mathrm{H}-0,1445 \mathrm{H}^{2} \mathrm{comR}^{2}=0,9943(\mathrm{P}<0,01)$, como é apresentado na Figura 1. As médias das concentrações de $\mathrm{N}$-uréia plasmáticas não diferiram entre os tratamentos, provavelmente, em virtude de as dietas experimentais serem isoprotéicas.

A concentração máxima de N-uréia plasmática correspondeu a $17,11 \mathrm{mg} / \mathrm{dL}$ às 5,93 horas após alimentação, o que não está de acordo com ELROD e BUTLER (1993), que relataram maior concentração de N-uréia plasmática entre 8 e 12 horas após

Tabela 5 - Custos com alimentação, receita e margem bruta e custo por kg de ganho de peso

Table 5 - Feed cost, gross income and margin and cost per $\mathrm{kg}$ of weight gain

\begin{tabular}{|c|c|c|c|c|c|c|}
\hline \multirow[t]{2}{*}{ Item } & \multicolumn{3}{|c|}{$\begin{array}{l}\text { Uréia } \\
\text { Urea }\end{array}$} & \multicolumn{3}{|c|}{$\begin{array}{l}\text { Cama de frango } \\
\text { Broilerlitter }\end{array}$} \\
\hline & $\begin{array}{c}\text { Sem } \\
\text { Without }\end{array}$ & $\begin{array}{c}\text { Levedura } \\
\text { Yeast }\end{array}$ & $\begin{array}{l}\text { Microbiota ruminal } \\
\text { Ruminal microbiota }\end{array}$ & $\begin{array}{c}\text { Sem } \\
\text { Without }\end{array}$ & $\begin{array}{c}\text { Levedura } \\
\text { Yeast }\end{array}$ & $\begin{array}{r}\text { Microbiota ruminal } \\
\text { Ruminal microbiota } \\
\end{array}$ \\
\hline $\begin{array}{l}\text { A - Custo da alimentação } \\
\text { Feed cost }\end{array}$ & & & & & & \\
\hline $\begin{array}{l}\text { Ração total oferecida } \\
(\mathrm{kg} \mathrm{MN} /[\text { nov•dia] }) \\
\text { Total fed diet } \\
(\text { kg as fed/[anim•day]) }\end{array}$ & 23,36 & 25,86 & 25,12 & 23,14 & 24,66 & 23,81 \\
\hline $\begin{array}{l}\text { Custo da ração ( } \mathrm{R} \$ / \mathrm{kg} \mathrm{MN}) \\
\text { Diet cost }(R \$ / \mathrm{kg} \text { as fed) }\end{array}$ & 0,035 & 0,036 & 0,035 & 0,048 & 0,049 & 0,049 \\
\hline $\begin{array}{l}\text { Custo com alimentação (R\$/nov/dia) } \\
\text { Feed cost (R\$/anim/day }\end{array}$ & 0,818 & 0,931 & 0,879 & 1,111 & 1,208 & 1,167 \\
\hline $\begin{array}{l}\text { B - Receita bruta } \\
\text { Gross income }\end{array}$ & & & & & & \\
\hline $\begin{array}{l}\text { Ganho de peso ( } \mathrm{kg} / \mathrm{dia}) \\
\text { Weight gain }(\mathrm{kg} / \text { day })\end{array}$ & 0,51 & 0,67 & 0,75 & 0,52 & 0,67 & 0,68 \\
\hline $\begin{array}{l}\text { Preço pago ao produtor }(\mathrm{R} \$ / \mathrm{kg}) \\
\text { Price paid to the feeders }\end{array}$ & 3,50 & 3,50 & 3,50 & 3,50 & 3,50 & 3,50 \\
\hline $\begin{array}{l}\text { Receita bruta }(\mathrm{R} \$ / \text { nov/dia }) \\
\text { Gross income }(\mathrm{R} \$ / \text { anim/day) }\end{array}$ & 1,79 & 2,35 & 2,63 & 1,82 & 2,35 & 2,38 \\
\hline $\begin{array}{c}\text { C- Margem bruta }(\mathrm{R} \$ / \text { nov/dia }) \\
\text { Gross margin }(R \$ / \text { anim/day) }\end{array}$ & 0,97 & 1,41 & 1,75 & 0,71 & 1,14 & 1,21 \\
\hline $\begin{array}{l}\text { D - Custo } / \mathrm{kg} \text { de ganho de peso } \\
\text { Cost } / \mathrm{kg} \text { of weight gain }\end{array}$ & 1,60 & 1,39 & 1,17 & 2,13 & 1,80 & 1,71 \\
\hline
\end{tabular}


alimentação. Entretanto, BUTLER et al. (1995) descreveram concentração máxima de $\mathrm{N}$-uréia sangüíneo entre 4 e 6 horas após alimentação, devido ao catabolismo da proteína degradável consumida.

As elevadas concentrações de $\mathrm{N}$-uréia plasmáticas obtidas neste trabalho, provavelmente, estariam aumentando a exigência de energia dietética e poderiam influenciar a performance reprodutiva das novilhas.

Observa-se, na Tabela 5, que o custo com alimentação das dietas suplementadas com cama de frango foi maior que o das dietas suplementadas com uréia. A adição de levedura ou microbiota ruminal liofilizada aumentou o custo da alimentação em todos os tratamentos. Entretanto, a receita bruta das dietas suplementadas com probióticos foi maior em relação às dietas suplementadas com uréia e às suplementadas com cama de frango. Dessa forma, como não se observou diferença no ganho em peso das novilhas, em relação à fonte de nitrogênio não-protéico, as dietas à base de cana-de-açúcar suplementadas com uréia foram economicamente mais viáveis, pois apresentam menor custo por quilo de ganho de peso e maior margem bruta. Observa-se também que a adição de probiótico foi economicamente viável.

\section{Conclusões}

A substituição parcial da uréia pela cama de frango, como fonte de NNP, não comprometeu o desempenho e o desenvolvimento de novilhas leiteiras mestiças alimentadas com dietas à base de cana-deaçúcar, mas reduziu a economicidade das dietas.

A suplementação das dietas com levedura ou microbiota ruminal melhorou o desempenho, o desenvolvimento e a economicidade.

\section{Referências Bibliográficas}

ANUALPEC 97. São Paulo: FNP. p.329.

AOAC. 1975. Association of Analytical Chemists. Official methods of analysis. 12. ed. Washington, D.C. 1094p.

AROEIRA, L.J.M., SILVEIRA, M.I., LIZIEIRE, R.S. et al. 1993. Degradabilidade no rúmen e taxa de passagem da canade-açúcar mais uréia, do farelo de algodão e do farelo de arroz em novilhos mestiços europeu x zebu. R. Soc. Bras. Zootec., 22(4):552-564.

BAILE, C.C., FORBES, J.M. 1974. Control of feed intake and regulation of energy balance in ruminants. Physiol. Reviews, 54(1):160-213.

BUTLER, W.R., CHERNEY, D.J.R., ELROD, C.C. Milk urea nitrogen (mun) anlysis: field trial results on conception rates and dietary inputs. In: CORNELL NUTRITION CONFERENCE FOR FEED MANUFACTURERS, 57,
Rochester, N.Y. Proceedings... Ithaca, N.Y.: Cornell University, 1995. p.89-95

ELROD, C.C., BUTLER, W.R. 1993. Reduction of fertility and alteration of uterine $\mathrm{pH}$ in heifers fed excess ruminally degradable protein. J. Anim. Sci., 71(3):694-701.

LENG, R. A. 1988. Limitaciones metabolicas en la utilización de la caña de azucar y sus derivados para el crecimento y producción de leche en ruminantes. In: PRESTON, T.R., ROSALRS, M. (Eds.) Sistemas intensivos para la produción animaly de energia renovable com recursos tropicales. Cali, CIPAV. p.1-24.

MERTENS, D.R. Factors influencing feed intake in lactating cows: From theory to application using neutral detergente fiber. In: GA NUTRITION CONFERENCE, 46, 1985, Athens. Proceedings... Athens: University of Georgia, 1985. p.1-18.

MERTENS, D.R. Análise da fibra e sua utilização na avaliação e formulação de rações. In: SIMPÓSIO INTERNACIONAL DE RUMINANTES, REUNIÃO ANUAL DA SOCIEDADE BRASILEIRA DE ZOOTECNIA, 29, 1992. Lavras, MG. Anais... Lavras: SBZ, 1992, p.188-219.

MERTENS, D.R. 1987. Predicting intake and digestibility using mathematical models of ruminal function. J. Anim. Sci., 64(7):1548-1558.

MOREIRA, A.M., PAIVA, J.A., CRUZ, G.M. et al. 1987. Canade-açúcar (Saccharum officinarum L.) adicionada de uréia e farelo de arroz no ganho em peso de novilhas mestiças leiteiras. R. Soc. Bras. Zootec., 16(6):500-506.

NATIONAL RESEARCH COUNCIL - NRC. 1989. Nutrients requeriments of dairy cattle. $6 \mathrm{ed}$. Washington D.C., National Academy of Sciences. 158p.

NEWBOLD, C. J., WALLACE, R. J., CHEN, X. B. et al. 1995. Different strains of Saccharomyces cerevisiae differ in their effects on ruminal bacterial numbers in vitro and in sheep. $J$. Anim. Sci., 73(6):1811-1818.

OLIVEIRA, R.L. Cinética digestiva em novilhos submetidos a dietas com diferentes níveis de cama de frango e de suplemento à base de microbiota ruminal. Viçosa, MG, 1998. 69p. Dissertação (Mestrado em Zootecnia) - Universidade Federal de Viçosa, 1998.

ORSKOV, E.R., HOVELL, F.D. 1978. Digestion ruminal del heno (medida através de bolsas de dracon) en el ganado alimentado com caña de azucar o heno de pangola. Prod. Anim. Trop., 3:9-11.

PAIVA, J.A.J., MOREIRA, H.A., CRUZ, G.M. et al. 1991. Cana-de-açúcar associada à uréia/sulfato de amônio como volumoso exclusivo para vacas em lactação. R. Soc. Bras. Zootec., 20(1):90-99.

PEREIRA, O G., VALADARES FILHO, S.C., GARCIA, R. et al. 1996. Degradabilidade in vivo e in sito de de nutrientes e efeiciência de síntese de proteína microbiana, em bovinos, alimentados com cana-de-açúcar sob diferentes formas. $R$. Bras. Zootec., 25(4):763-777.

RADCLIFF, R.P., VANDEHAAR, M.J., SKIDMORE, A L. et al. 1997. Effects of diet and bovine somatotropin on heifer growth and mamary devolopiment. J. Dairy Sci., 80(9):1996-2003.

RODRIGUEZ, N.M. Pesquisas sobre dinâmica da fermentação ruminal e aprtição da digestão realizadas no Departamento de Zootecnia da Escola de veterinária da UFMG. In: SIMPÓSIO INTERNACIONAL SOBRE EXIGÊNCIAS NUTRICIONAIS DE RUMINANTES, Viçosa, MG, 1995. Anais...Viçosa: JARD, 1995. p.389-417.

SILVA, D.J. 1990. Análise de alimentos (métodos químicos e biológicos). Viçosa, MG: UFV, Impr. Univ. $166 \mathrm{p}$.

SILVA, P.R.C. Cama de frango e suplemento à de microbiota ruminal na alimentação de novilhas de rebanhos leiteiros: 
Rev. bras. zootec.

desempenho e avaliação econômica. Viçosa, MG, 1998.98p. Dissertação (Mestrado em Zootecnia) - Universidade Federal de Viçosa, 1998.

UNIVERSIDADE FEDERAL DE VIÇOSA (UFV). 1995. S.A.E.G. (Sistema de Análises Estatísticas e Genéticas). Viçosa, MG (Versão 5.0).

VAN SOEST, P.J. 1994. Nutritional ecology of the ruminant. 2.ed. Ithaca: Cornell. 476p.

VAN SOEST, P.J. ROBERTSON, J.B., LEWIS, B.A. 1991. Methods for dietary fiber, neutral detergente fiber, and nonstarch polysaccharides in relation to animal nutrition. $J$. Dairy Sci., 74(10):3583-3597.
VAN SOEST, P.J. 1965. Symposium on factors influencing the voluntary intake to chemical composition and digestibility. J. Anim Sci., 24(2):834-843.

WALLACE, R. J. 1994. Ruminal microbiology, biotechnology, and ruminant nutrition: progess and probems. J. Anim. Sci., 72(11):2992-3003.

Recebido em: 09/07/98

Aceito em: 05/12/98 